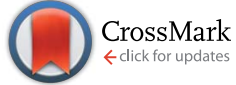

Cite this: RSC Adv., 2015, 5, 104472
Received 31st October 2015

Accepted 1st December 2015

DOI: $10.1039 /$ c5ra22898k

www.rsc.org/advances

\section{Bio-conversion of apple pomace into fumaric acid in a rotating drum type solid-state bench scale fermenter and study of the different underlying mechanisms}

\begin{abstract}
Ratul Kumar Das, ${ }^{a}$ Linson Lonappan, ${ }^{a}$ Satinder Kaur Brar*a and Mausam Verma ${ }^{\text {b }}$
Utilization of apple industry solid waste, apple pomace (AP) for the production of fumaric acid (FA) using a rotating drum type solid-state bench scale fermenter was studied under optimized conditions and different mechanisms underlying the conversion were investigated. The filamentous fungal strain, Rhizopus oryzae 1526 was used in the study. The solid-state fermentation was carried out in continuous rotation, intermittent rotation and static mode of the fermenter operations for a maximum of 21 days. Two different moisture contents $(70 \%$ and $50 \%$, w/w) of AP were applied for each batch. The highest FA concentration ( $138 \pm 9.11 \mathrm{~g}$ per $\mathrm{kg}$ dry weight of AP) was achieved at $50 \%$ moisture content and under continuous rotation after 14 days. Viability checking of the fungus showed maintenance of a high cell count $\left(2.74 \times 10^{8}\right.$ spores per $g$ dry apple pomace) during fermentation. Analysis of AP fibre composition confirmed the conversion of insoluble dietary fibers into soluble dietary fibers and utilization of the dietary fibres for FA production. Total phenolic content of AP was considerably increased (by around $86 \%$ ) from $185 \pm 10.5$ to $345 \pm 8.5 \mathrm{mg}$ per g lyophilizate after 18 days. LC/MS/MS analysis confirmed the consumption of sugars (glucose fructose and sucrose) present in AP by the fungus during fermentation. The presence of different phenolic compounds and changes in their content after fermentation was also confirmed by LC/MS/MS analysis. Two other operating conditions produced $82 \pm 6.8$ and $58 \pm 8.5 \mathrm{~g}$ of FA per kg dry weight of AP, respectively after 18 days of fermentation.
\end{abstract}

\section{Introduction}

In recent times, advancement in biotechnological approaches and utilization of the natural ability of microorganisms has enabled the bioconversion of different waste biomass into valueadded products. The global message of developing a sustainable and green option for each chemically produced product has been very successful for many platform chemicals. ${ }^{1}$ Although, the number of reports in this research area are piling up at a great pace, scale-up studies are scarce and this might be caused by the unfeasibility constraints generated as a result of experimental volumetric expansion from laboratory to industrial scale. Among the different biotechnological processes, fermentation has been the most explored and successful option for the bioproduction of many high-value chemicals. In this regard, the recent progress made in the biological production of 'fumaric acid' (FA), the organic acid with diverse applications is worthy of attention. ${ }^{2-4} \mathrm{FA}$ and its ester derivatives have emerged as a multifaceted molecule

INRS-ETE, Université du Québec, 490 Rue de la Couronne, Québec (QC) G1K 9A9, Canada. E-mail: satinder.brar@ete.inrs.ca; Fax: +1 418654 2600; Tel: +1 418654 3116

${ }^{b} \mathrm{CO}_{2}$ Solutions Inc., 2300, rue Jean-Perrin, Québec, Québec G2C 1T9, Canada with newer applications in bio-medical field with previous conventional uses. ${ }^{5-9}$ The growing demand of FA can be well understood by looking at its current market volume statistics. The report published in 2014 stated that the current market volume of FA is around $240000 \mathrm{t}$ and the projected market volume is $350000 \mathrm{t}$ by $2020 .{ }^{10}$ Biological route of FA production over chemical method is being preferred due to human and environmental health issues. ${ }^{\mathbf{4 1 1}}$ In fact, FA has been identified as one of the top ten value-added chemical that can be produced from sugars by means of biological conversion. ${ }^{12}$ In the last four decades, lots of efforts have been made to produce FA from different waste carbon sources employing various microorganisms in particular, different strains of the filamentous fungus Rhizopus oryzae.,13 Bibliographic data shows that most of the fermentation studies carried out so far on FA production were submerged fermentation (SmF); while experimentation on solidstate fermentation (SSF) based FA production is yet to draw much attention. SSF has many technical advantages over SmF and this issue has been extensively reviewed by experts. ${ }^{\text {14-16 }}$ However, finding a suitable solid substrate with good potential of serving the purposes of carbon, micro and macro nutrients is vital for SSF. Moreover, for every new combination of a solid substrate and microbial strain, extensive study on process optimization is 
required. In this regard, the apple industry origin waste solid biomass 'apple pomace' (AP), can be considered as SSF substrate. The AP is the left over solid residue after apples are pressed for juice collection and separated from the liquid. Although, AP is an apple industry waste by-product, it represents around $20-35 \%$ of the original fruits. ${ }^{17,18} \mathrm{AP}$ is shown to be a very good source of nutrition for microorganisms and this also make AP highly prone to microbial attack and thus unsafe for environmental disposal. ${ }^{19-23}$ High apple production in Canada (around 382 million $\mathrm{kg}$ as of 2014 report) and demand for apple juice makes AP production unavoidable. ${ }^{24}$ Looking at the possibility of utilizing AP as a good carbon source for FA producing fungal strain such as Rhizopus oryzae 1526 AP was considered as a solid substrate for FA production in a rotating drum type solid-state bench scale fermenter. The selection of $R$. oryzae 1526 for FA production was made on the basis of important sequential findings of decade old research on FA production ability of this fungal strain. In the 1950s and 1980s the genus Rhizopus gained tremendous importance as different species of this genus were found to capable of producing FA at commercial level. The companies 'National Distillers and Chemical Corporation' (1958) and 'Du Pont' (1986) manufactured FA employing species of Rhizopus. ${ }^{25-27}$ For species selection, advantage of using Rhizopus oryzae over other FA producing species (such as $R$. nigricans, $R$. formosa and $R$. arrhizus) is supported by previous findings. It has been shown that Rhizopus oryzae has simple nutritional requirement for its growth and metabolism and this facilitates the utilization of low cost carbon sources. Moreover, Rhizopus oryzae species resulted in the highest productivity $\left(4.25 \mathrm{~g} \mathrm{~L}^{-1} \mathrm{~h}^{-1}\right)$ of FA in a rotary reactor. ${ }^{2}$ These research outcomes have established $R$. oryzae as the frontliner in the production of FA. To be specific in strain selection, it's worth mentioning that among different strains of $R$. oryzae tested for FA production, the strain NRRL 1526 is one of the best strains. ${ }^{28}$ Thus, considering the general acceptance, technical feasibility and advantages over other FA producing species and strains, the fungal strain Rhizopus oryzae 1526 (to be called $R$. oryzae hereafter) was selected for the present research work. To the best of author's knowledge, no prior study with rotating drum type solid-state bench scale fermenter has been carried out for FA production and this implies the novelty elements of the present study.

\section{Experimental}

\subsection{Materials}

The fungal strain used for FA production was Rhizopus oryzae 1526 and was procured from Agricultural Research Services (ARS) culture collection, IL, USA. The apple industry waste biomass with rice husk was procured from Lassonde Inc., Rougemont, Montreal, Canada. All the chemicals used in the present study were of analytical grade and purchased from Fisher Scientific (Ottawa, Ontario, Canada).

\subsection{Culture of Rhizopus oryzae 1526}

The procured fungal strain was revived on potato dextrose agar (PDA) slant after incubating at $37 \pm 1{ }^{\circ} \mathrm{C}$ for 4 days (d) and then propagated on Petri dishes with PDA. The inoculated PDA Petri dishes were incubated for a period of $72 \mathrm{~h}$ at $37 \pm 1{ }^{\circ} \mathrm{C}$. After 3 $\mathrm{d}$ of incubation, the fully grown and sporulated fungus was washed with distilled water $\left(\mathrm{d} \cdot \mathrm{H}_{2} \mathrm{O}\right)$ and the sporangiospores were collected by filtering through glass wool. The stock of the spore suspension was maintained at $1 \times 10^{8}$ spores per $\mathrm{mL}$ and stored at $4 \pm 1{ }^{\circ} \mathrm{C}$ for regular uses. For long time storage, spore suspension was mixed with $20 \%$ glycerol and kept at $-80{ }^{\circ} \mathrm{C}$.

\subsection{Rotating drum type solid-state bench scale fermenter: operating conditions}

An in situ sterilizable solid-state bench scale fermenter (BSF) of $12 \mathrm{~kg}$ capacity (Model: Terrafor-IS, Make: Infors HT, Switzerland) with maximum 3-4 kg working volume was used for the present study. To prepare for each batch of SSF, operating conditions of BSF was set as follows: (a) aeration rate of $1 \mathrm{vvm}$ (rotameter controllable); (b) maximum operating pressure: +2.0 bar; (c) feed 1 pump (condensate line return to vessel) at 10\%; (d) feed 2 pump connected to reagent bottle (filled with sterilized water) with the T-piece and manually controlled; (e) push valves of condensate return lines were opened and; (f) operating temperature (for inoculation) was set at $30 \pm 1{ }^{\circ} \mathrm{C}$.

\subsection{Substrate preparation for solid-state fermentation}

To prepare for SSF, oven dried AP (with 6-10\% of moisture content; MC\%) was first moisture adjusted ( 50 and $70 \%, \mathrm{w} / \mathrm{w}$ ) by homogenously mixing with distilled water $\left(\mathrm{d} . \mathrm{H}_{2} \mathrm{O}\right)$. For each batch, $1 \mathrm{~kg}$ (dry weight) of AP was used. In situ sterilization of MC adjusted AP was carried out at $121 \pm 1{ }^{\circ} \mathrm{C}$ for $20 \mathrm{~min}$. Push valves of condensate return lines were closed during sterilization. A test run was done to see the change in the MC of the AP substrate before and after sterilization. Sterilized AP was allowed to cool down to the inoculation temperature of $30 \pm 1$ ${ }^{\circ} \mathrm{C}$. Before inoculation, $\mathrm{pH}$ of sterilized AP was adjusted to 5.56.0 by aseptically adding required amount of sterilized $\mathrm{CaCO}_{3}$ powder and rotating the BSF continuously for at least $12 \mathrm{~h}$ at 5 rpm. Well mixed AP samples were collected through the sample collection port (Tri-Clamp port) under aseptic condition (flaming method) and analyzed for changes in $\mathrm{MC}$ and $\mathrm{pH}$. If required, $\mathrm{MC}$ and $\mathrm{pH}$ was further adjusted before inoculation.

\subsection{Inoculation and solid-state fermentation}

After cooling down to inoculation temperature $\left(30 \pm 1{ }^{\circ} \mathrm{C}\right)$, AP was inoculated with $R$. oryzae spores at a concentration of $1 \times$ $10^{7}$ spores per $g$ dry AP. The inoculation was done following standard procedure for BSF. Briefly, spore suspension was filled in sterilized syringe and pierced through the septum (piercing membrane) in the $19 \mathrm{~mm}$ port of the BSF under aseptic conditions (flaming method) and later set to SSF conditions. For optimization of FA production, BSF was run under different SSF conditions for a maximum of $21 \mathrm{~d}$. Two parameters, viz. MC of AP and mode of rotation of BSF were considered. Three modes of operation (continuous rotation, intermittent rotation and static mode) of BSF were tested for FA production. In the continuous mode of operation, $2 \mathrm{rpm}$ for counter-clockwise for $12 \mathrm{~h}$ and $2 \mathrm{rpm}$ clockwise for the next every $12 \mathrm{~h}$ was followed. 
For the intermittent rotation, programme was set at $2 \mathrm{rpm}$ for $60 \mathrm{~min}$ counter-clockwise and at $2 \mathrm{rpm}$ for $60 \mathrm{~min}$ clockwise, after every $12 \mathrm{~h}$. AP adjusted with $50 \%$ and $70 \%(\mathrm{w} / \mathrm{w})$ of $\mathrm{MC}$ were used for each run of SSF with different modes of operation.

\subsection{Sample collection and downstream processing}

For FA estimation, $5 \mathrm{~g}$ of fermented samples was collected through the Tri-Clamp port of BSF under aseptic condition (flaming method) at $3 \mathrm{~d}, 5 \mathrm{~d}, 7 \mathrm{~d}, 9 \mathrm{~d}, 12 \mathrm{~d}, 14 \mathrm{~d}, 16 \mathrm{~d}, 18 \mathrm{~d}$ and $21 \mathrm{~d}$ intervals of SSF. Sterilized d. $\mathrm{H}_{2} \mathrm{O}$ at $1: 10$ solid to liquid ratio was mixed with the collected samples and then kept in a shaking incubator at $200 \mathrm{rpm}$ at $30 \pm 1{ }^{\circ} \mathrm{C}$ for $1 \mathrm{~h}$. For the removal of solid residues and fungal mycelia from the mixture, samples were filtered through glass wool. Downstream processing of the fermented broth samples was carried out following the standard method. ${ }^{29}$ Briefly, filtered samples were treated with simultaneous heating and acidification $\left(90 \pm 1{ }^{\circ} \mathrm{C}\right.$, $\left.5 \mathrm{~N} \mathrm{H}_{2} \mathrm{SO}_{4}\right)$ until clear and later centrifuged $(8000 \times \mathrm{g}, 10 \mathrm{~min}$, $20 \pm 1{ }^{\circ} \mathrm{C}$ ) and supernatants were collected. FA concentrations in the supernatant were estimated by using high performance liquid chromatography (HPLC) technique and the FA concentrations were expressed in $\mathrm{g}$ per $\mathrm{kg}$ dry apple pomace.

\subsection{Analytical techniques}

Estimation of total dietary fibre (TDF), insoluble dietary fibre (IDF) and soluble dietary fibre (SDF) of unfermented and fermented dried AP samples were carried out following the AOAC (Association of Official Analytical Chemists) methods. ${ }^{30}$

To determine the water holding capacity (WHC) of AP, the previously mentioned method was followed with some modifications. ${ }^{31}$ Briefly, 5 grams of dried AP was vigorously mixed with $100 \mathrm{~mL}$ of d. $\mathrm{H}_{2} \mathrm{O}$ for $10 \mathrm{~min}$ and then centrifuged at $8000 \times g$ for $15 \mathrm{~min}$ at $20 \pm 1{ }^{\circ} \mathrm{C}$. The supernatant was carefully discarded and the centrifuge bottles with AP pellets were kept inverted until free water droplets stopped running from the AP pellets. Finally, the MC of the AP pellets was determined following standard method and WHC $\left(\mathrm{g} \mathrm{g}^{-1}\right)$ was accordingly calculated. ${ }^{32}$

For $\mathrm{pH}$ measurement, $2 \mathrm{~g}$ fermented AP sample was mixed with $20 \mathrm{~mL}$ of $\mathrm{d} . \mathrm{H}_{2} \mathrm{O}$ and kept for vortexing for $10 \mathrm{~min}$ and filtered through filter paper (Whatman \# 4). Filtrate was analyzed for $\mathrm{pH}$ measurement using a $\mathrm{pH}$ meter equipped with glass electrode (EcoMet P25). Oven-dry method was used for the analysis of moisture content (MC) of AP samples (raw and fermented). ${ }^{26}$ Briefly, about $5 \mathrm{~g}$ of AP sample was allowed to dry at $60 \pm 1{ }^{\circ} \mathrm{C}$ until a constant weight was achieved. The MC in PPSW was calculated as per eqn (1):

$$
\mathrm{MC}=\frac{\text { initial weight }- \text { oven dry weight }}{\text { initial weight }} \times 100
$$

For the extraction of phenolic compounds from the AP (raw and fermented) samples, the procedure of previously mentioned method was followed..$^{33}$ The phenolic content was estimated by Folin-Ciocalteu method taking gallic acid as standard. Optical density (OD) was measured at $\lambda_{\max }=765 \mathrm{~nm}$ using a 96 well plate reader (BioTek Instruments, Epoch, USA).
For the identification and estimation of different phenolic compounds, liquid chromatography-mass spectroscopy (LC/ MS-MS) analysis was performed. To prepare sample for LC/ MS-MS analysis, lyophilized phenolic extract was first resuspended in water and methanol $(1: 1)$ and later analyzed. ${ }^{32}$

To prepare samples for sugar (glucose, fructose and sucrose) consumption analysis, $5 \mathrm{~g}$ of oven-dried (for both raw and fermented) sample was mixed with $30 \mathrm{~mL}$ of d. $\mathrm{H}_{2} \mathrm{O}$ and kept under shaking condition for $1 \mathrm{~h}$ at $200 \mathrm{rpm}$ and $25 \pm 1{ }^{\circ} \mathrm{C}$. The samples were then centrifuged $(8000 \times g$ for $15 \mathrm{~min}$ at $25 \pm 1$ ${ }^{\circ} \mathrm{C}$ ) and collected supernatants were checked for $\mathrm{pH}(5.0)$ and if required, the $\mathrm{pH}$ was adjusted with $\mathrm{NaOH}$ solution $(10 \mathrm{~N})$ and paper filtered (Whatman \# 44). Finally, filtrates were syringefiltered $(0.45 \mu \mathrm{m})$ and analyzed for sugars using LC/MS-MS method.

For viability check of $R$. oryzae at different time intervals of $\mathrm{SSF}$, around $100 \mu \mathrm{L}$ sample (prepared for downstream processing for FA estimation) was taken and total spore count (per gram dry AP) was done using a haemocytometer.

The quantification of FA in the downstream processed AP samples was carried out by HPLC technique. Sample preparation for HPLC analysis was carried out following standard procedure. $^{34}$ The specification of the HPLC used was as follows: System: DIONEX DX500, with an Acclaim OA, $5 \mu \mathrm{m},(4.6 \times 150$ $\mathrm{mm}$ ) column with a refractive index detector (PDA-100 DIONEX, $\mathrm{UV}, 210 \mathrm{~nm}$ ). The mobile phase was $2.5 \mathrm{mM}$ methanesulfonic

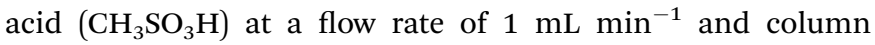
temperature of $30 \pm 1{ }^{\circ} \mathrm{C}$. For the identification and estimation of sugars (glucose, fructose and sucrose) and different phenolic compounds (gallic acid, ferulic acid, 4-amino-benzoic acid, vanillic acid and vanillin) in the fermented AP samples, LC/MS/ MS technique was employed. The technical details of the LC/ MS/MS instrument used for the analysis were: (a) for sugar estimation: Thermo TSQ Quantum model, equipped with an Electrospray Ionization (ESI) in negative ion mode; Zorbax Carbohydrate $(4.6 \mathrm{~mm} \times 150 \mathrm{~mm} ; 5 \mu \mathrm{m}$, Agilent) analytical column; $75 \%$ acetonitrile; $0.1 \% \mathrm{NH}_{4} \mathrm{OH} ; 25 \%$ water and $0.1 \%$ $\mathrm{NH}_{4} \mathrm{OH}$ mobile phase and $10 \mu \mathrm{L}$ injection volume. Glucose-D2, D-(-)-fructose and sucrose (all from Sigma) was used as the internal standards; (b) for phenolic compound estimation: Thermo TSQ Quantum model, equipped with an Electrospray Ionization (ESI) in negative ion mode, Thermo Scientific BetaBasic C18 LC column $(100 \mathrm{~mm} \times 2.1 \mathrm{~mm}$; $3 \mu \mathrm{m})$; mobile phase of methanol and acidified water $(0.1 \%$ acetic acid $)$ at a ratio of 17.5 : 82.5; flow rate of $0.3 \mathrm{~mL} \mathrm{~min}^{-1}$ and $20 \mu \mathrm{L}$ injection volume. Gallic acid, ferulic acid, 4-amino-benzoic acid, vanillic acid and vanillin (all from Sigma) were used as internal standards.

\section{Results and discussion}

\subsection{Effects of AP moisture content and BSF mode of rotations on FA production}

The FA concentrations ( $\mathrm{g}$ per kg dry AP) achieved with $70 \%$ (w/ $\mathrm{w})$ and $50 \%(\mathrm{w} / \mathrm{w}) \mathrm{MC}$ of $\mathrm{AP}$ is shown in Fig. 1 and 2, respectively. The FA concentration varied under continuous rotation, intermittent rotation and static mode of BSF. At $70 \%(\mathrm{w} / \mathrm{w})$ of 
MC and under continuous rotation, the FA concentration reached up to $22.6 \pm 3.5 \mathrm{~g} \mathrm{~kg}^{-1}$ at the end of $5 \mathrm{~d}$ of SSF. From 5 $\mathrm{d}$ onwards, production of FA started decreasing and at the end of $12 \mathrm{~d}$ of SSF, only $4.5 \pm 1.8 \mathrm{~g}$ per $\mathrm{kg}$ of FA was recorded. With $50 \%(\mathrm{w} / \mathrm{w})$, there was a continuous increase in the FA concentration from $5 \mathrm{~d}$ to $14 \mathrm{~d}$ of SSF and then became static onwards. At the end of the $14 \mathrm{~d}$ of SSF, FA concentration reached $138 \pm$ $9.1 \mathrm{~g} \mathrm{~kg}^{-1}$. In comparison to the highest FA concentration (22.6 $\pm 3.5 \mathrm{~g} \mathrm{~kg}^{-1}$ ) achieved with $70 \%(\mathrm{w} / \mathrm{w})$, the FA production was enhanced by about 6.1 folds. In the intermittent mode of rotation, similar trend of effects of MC and mode of rotation of BSF on FA production was observed. AP with $70 \%(w / w)$, FA concentration started increasing on $5 \mathrm{~d}$ onwards and reached up to $31 \pm 3.1 \mathrm{~g} \mathrm{~kg}^{-1}$ at the end of $9 \mathrm{~d}$ of SSF and declined thereafter. For $50 \%(\mathrm{w} / \mathrm{w}) \mathrm{MC}$, the production level of FA was $82 \pm 6.8 \mathrm{~g} \mathrm{~kg}^{-1}$ at the end of $18 \mathrm{~d}$ of SSF. In the static mode of rotation of $\mathrm{BSF}$, with $70 \%(\mathrm{w} / \mathrm{w})$ of $\mathrm{AP}, \mathrm{FA}$ concentration reached $17.3 \pm 3.5 \mathrm{~g} \mathrm{~kg}^{-1}$ at the end of $12 \mathrm{~d}$ of SSF. When experimented for $50 \%(\mathrm{w} / \mathrm{w}) \mathrm{MC}$, the $\mathrm{FA}$ production was increased to $58 \pm 8.5 \mathrm{~g} \mathrm{~kg}^{-1}$ after $18 \mathrm{~d}$ of SSF.

The MC of SSF substrate is a fundamental parameter for controlling the growth and metabolism of filamentous fungi. In general, a MC that allows to maintain the conditions: (a) no free-moving water and (b) air as the continuous phase are considered suitable for SSF. ${ }^{\mathbf{1 4 - 1 6}}$ These conditions are met by optimization studies on each new combination of SSF substrate and fungal strain. In the present SSF study with AP and $R$. ory$z a e$, the production profile of FA changed as responses to the changes made in the MC of AP. Apart from MC, mode of operations (continuous rotation, intermittent rotation and static mode) of BSF also influenced the FA production level. Thus, it will be pertinent to elaborate the obtained results for each combination of MC and mode of operations of BSF. The variations in the FA production profiles under continuous mode of rotation of BSF can be well explained with some basic principles of SSF. It was observed that, under continuous mode of

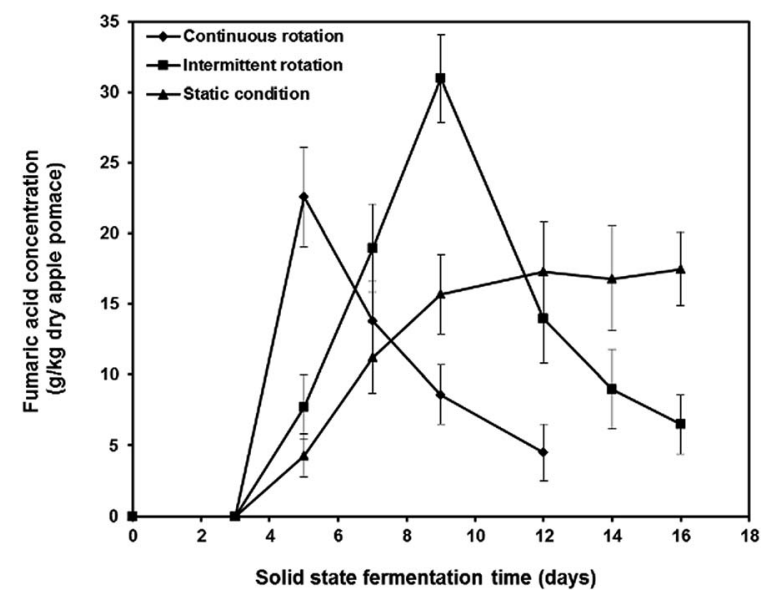

Fig. 1 The fumaric acid concentrations (g per kg dry apple pomace) achieved with $70 \%(\mathrm{w} / \mathrm{w})$ of moisture content of apple pomace under continuous rotation, intermittent rotation and static mode of the bench scale fermenter.

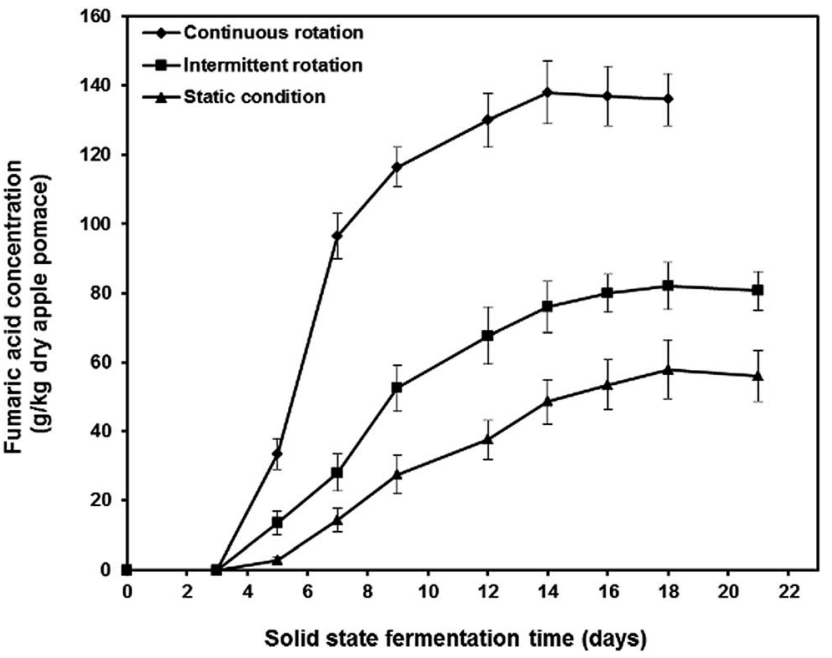

Fig. 2 The fumaric acid concentrations (g per kg dry apple pomace) achieved with $50 \%(\mathrm{w} / \mathrm{w})$ of moisture content of apple pomace under continuous rotation, intermittent rotation and static mode of the bench scale fermenter.

rotation, AP with $70 \%(\mathrm{w} / \mathrm{w})$ formed agglomerates of different sizes $(4-5 \mathrm{~cm})$ and shapes after $5 \mathrm{~d}$ of SSF. Most of the agglomerates were roughly spherical shaped and highly compacted, while others were of irregular shapes. Only small fractions of AP were left without agglomeration. However, this was not the case with $50 \%(\mathrm{w} / \mathrm{w}) \mathrm{MC}$ of AP under continuous mode of rotation of BSF. No agglomerates were formed up to $18 \mathrm{~d}$ of SSF and before this time period, FA reached its maximum concentration $138 \pm 9.1 \mathrm{~g} \mathrm{~kg}^{-1}$ at the end of $14 \mathrm{~d}$ of SSF. Although, it was difficult to pinpoint the exact contributing factor for the agglomeration of AP, still high MC of AP and continuous rotation might have helped in the process. To rule out the possibility of any influence of speed (rpm) and direction (clockwise and anticlockwise) of rotation of BSF on agglomeration of AP, apart from $2 \mathrm{rpm}$, three more different speeds (1, 3 and 4) at clockwise or anticlockwise directions, were experimented with $70 \%(\mathrm{w} / \mathrm{w})$ MC. In all applied speeds, agglomeration of AP could not be avoided. Direction of BSF rotation did not show any impact on the agglomeration of AP. In either clockwise or anticlockwise direction of BSF, there was agglomeration with 1, 3 and 4 rpm speeds. Under all such applied conditions, AP resulted in lower FA production (data not shown). The continuous rotation mode of BSF selected for the present study was intended for the proper mixing of the substrates with $\mathrm{CaCO}_{3}(\mathrm{pH}$ maintenance) and aeration throughout the substrate during SSF. Worth mentioning, the design of the BSF allowed aeration only on the top layer of the solid substrate and the approximate height of the $1 \mathrm{~kg}$ AP inside the vessel of BSF was around 11-12 cm. Penetration of air to the middle and lower portions of AP layer of this height, was not possible without rotation. FA being an aerobic process, without proper supply of air, production level is considerably affected. ${ }^{35}$ The agglomeration of AP under continuous rotation might be the consequence of high $\mathrm{MC}$ as it is of general acceptance that high MC of SSF substrate can cause particle agglomeration 
along with limiting the air transfer. ${ }^{\mathbf{1 4}}$ This became evident as agglomeration of AP was not caused at $50 \%(\mathrm{w} / \mathrm{w}) \mathrm{MC}$ of $\mathrm{AP}$ under continuous mode of rotation. It was obvious that agglomerates being highly compacted were not supportive of air supply and fungal growth inside and thus lowered FA production. Although, AP formed smaller agglomerates in the intermittent mode of rotation with $70 \%(\mathrm{w} / \mathrm{w})$, much of the AP was left as free biomass as compared to continuous mode of rotation. The 2.64 folds enhancement in FA concentration for 50\% (w/w) MC could be attributed to non-agglomeration behaviour of AP. However, $82 \pm 6.8 \mathrm{~g}$ per $\mathrm{kg}$ of FA concentration was achieved at the end of $18 \mathrm{~d}$ of SSF and this was much longer incubation compared to with $70 \%(\mathrm{w} / \mathrm{w})$. It was obvious that $50 \%(\mathrm{w} / \mathrm{w})$ MC supported higher FA production but intermittent mode of rotation might have supported air supply less efficiently as compared to continuous mode of rotation and this delayed the process of FA production. Under static conditions, air supply will be sufficient only on the top part of AP and cannot reach most portions of the 11-12 cm height AP bed. This caused least FA production as compared to continuous and intermittent mode of BSF rotations for both applied MCs. To ensure that estimation of FA was carried out for the whole AP, the substrate was first mixed with a sterilized iron rod through the Tri-Clamp port of BSF under aseptic condition (flaming method) and samples were collected for FA estimation. The variation in FA concentrations with $50 \%(\mathrm{w} / \mathrm{w})$ and $70 \%(\mathrm{w} / \mathrm{w})$ MC may be due to the limitation of air supply at higher MC compared to lower MC of AP. The overall findings on the effects of $\mathrm{MC}$ and BSF mode of rotation on FA production suggested that $50 \% \mathrm{MC}$ and continuous rotation (2 rpm) were optimum for enhanced FA production with $\mathrm{AP}$ and $R$. oryzae.

\subsection{Water holding capacity (WHC) of AP}

The WHC of AP was found to be around 8.12 $\pm 1.25 \mathrm{~g}$ water per gram of AP dry weight. This value is comparable to previous findings. ${ }^{31,36}$ The higher WHC of AP showed AP fibres to be good water binder. For the long-term maintenance of MC by a solid substrate, higher WHC is important. As SSF represents a condition of no free-moving water, WHC actually is the maximum water content for the dissolution of solutes (nutrients) in aqueous phase throughout the substrate. ${ }^{37,38}$ In the present study, the spore germination, propagation and sporulation of the fungus $R$. oryzae were supported under SSF conditions. These fungal processes used sufficient amount of water held by AP. Moreover, agglomeration of AP at $70 \% \mathrm{MC}$ was also caused by the high WHC of AP. High WHC and collision of AP particles during the rotational motion of the drum of BSF led to adhesion of AP particles and hence formation of agglomerates. This was also supportive of the interstitial liquid induced agglomeration of solid particles. ${ }^{39}$

\subsection{Sugar consumption and FA production}

To find out the exact carbon source for the fungus $R$. oryzae during SSF, concentrations (mg per $\mathrm{g}$ dried AP) of sugar molecules (glucose, fructose and sucrose) in the raw (before SSF) and fermented AP samples were estimated. The residual concentrations $\left(\mathrm{mg} \mathrm{g}^{-1}\right)$ of these three sugar molecules at different time intervals of SSF are shown in Fig. 3A. The initial concentrations of glucose, fructose and sucrose were estimated to be $128 \pm 5.6,270 \pm 7.5$ and $35 \pm 4.5 \mathrm{mg}$ per $\mathrm{g}$ of dried AP samples, respectively. Fructose was consumed very fast and at the end of $7 \mathrm{~d}$ of SSF, the residual concentration of fructose was found to be $19 \pm 3.5 \mathrm{mg} \mathrm{g}^{-1}$. After same SSF time $(7 \mathrm{~d})$, the residual glucose concentration was estimated to be $8.6 \pm 1.5 \mathrm{mg}$ $\mathrm{g}^{-1}$. At the end of $12 \mathrm{~d}$ of SSF, the residual fructose concentration decreased to $4.5 \pm 1.4 \mathrm{mg} \mathrm{g}^{-1}$. In Fig. 3A, it was important to observe that residual glucose concentration suddenly increased from $8.6 \pm 1.5$ to $36 \pm 2.8 \mathrm{mg} \mathrm{g}^{-1}$ after $7 \mathrm{~d}$ of SSF and was brought down from $36 \pm 2.8$ to $5 \pm 1.1 \mathrm{mg} \mathrm{g}^{-1}$ after $14 \mathrm{~d}$. Consumption of sucrose was slowest, because the microorganisms are favorable to use glucose and fructose first. Sucrose reached its minimum residual concentration of $3.2 \pm 1.2 \mathrm{mg}$ $\mathrm{g}^{-1}$ after $14 \mathrm{~d}$ of SSF. To have a better understanding of the preferential consumption of the sugar molecules under SSF conditions, sugar consumption rates ( $\mathrm{mg}$ per $\mathrm{g}$ dried AP per $\mathrm{h}$ ) were estimated for glucose, fructose and sucrose. The results are displayed in Fig. 3B. At the end of $3 \mathrm{~d}$, glucose consumption rate was around $0.72 \pm 0.1 \mathrm{mg} \mathrm{g}^{-1} \mathrm{~h}^{-1}$. For fructose, consumption rate was much higher $\left(2.08 \pm 0.2 \mathrm{mg} \mathrm{g}^{-1} \mathrm{~h}^{-1}\right)$ in the first $3 \mathrm{~d}$ of SSF. As mentioned before, after $7 \mathrm{~d}$ of SSF, glucose concentration increased from $8.6 \pm 1.5$ to $36 \pm 2.8 \mathrm{mg}$ $\mathrm{g}^{-1}$ and this corresponded to the negative value $(-0.57 \pm 0.1 \mathrm{mg}$ $\mathrm{g}^{-1} \mathrm{~h}^{-1}$ ) of glucose consumption rate recorded after $9 \mathrm{~d}$ of SSF. At the end of $5 \mathrm{~d}$, fructose consumption rate decreased to $0.89 \pm$ $0.1 \mathrm{mg} \mathrm{g}^{-1} \mathrm{~h}^{-1}$ and in between $5 \mathrm{~d}$ to $7 \mathrm{~d}$, it was slightly increased from $0.89 \pm 0.15$ to $1.2 \pm 0.2 \mathrm{mg} \mathrm{g}^{-1} \mathrm{~h}^{-1}$. Similar changes in consumption rate was also observed for glucose. From $9 \mathrm{~d}$ onwards, consumption rate of glucose and fructose started decreasing until $16 \mathrm{~d}$ and $12 \mathrm{~d}$ respectively and then remained almost unchanged. For sucrose, the consumption rate was slower $\left(0.1 \pm 0.05 \mathrm{mg} \mathrm{g}^{-1} \mathrm{~h}^{-1}\right)$ in the first $5 \mathrm{~d}$ and increased to $0.34 \pm 0.1 \mathrm{mg} \mathrm{g}^{-1} \mathrm{~h}^{-1}$ after $7 \mathrm{~d}$ of SSF. At the end of $9 \mathrm{~d}$, consumption rate considerably decreased to $0.014 \pm 0.01$ $\mathrm{mg} \mathrm{g}^{-1} \mathrm{~h}^{-1}$ and maintained negligible changes onwards. Overall, fructose consumption rate was highest among the three sugar moieties followed by glucose and sucrose.

During SSF under continuous rotation with $50 \% \mathrm{MC}$, the fungus utilized the sugar molecules in a preferential manner. This is a well-known fact that microorganisms prefer hexose sugars for their metabolic activities. ${ }^{40}$ In the present study, the fungus consumed the easily available hexose sugar moieties (glucose and fructose) and bioconverted it into FA. As mentioned earlier, under continuous rotation with $50 \%$ MC, FA concentration reached the highest concentration of $138 \pm 9.1 \mathrm{~g}$ $\mathrm{kg}^{-1}$ at the end of $14 \mathrm{~d}$ of SSF. This was quite supportive, if residual concentrations of glucose and fructose at the end of 14 $\mathrm{d}$ are considered. The increase in glucose concentration from $8.6 \pm 1.5$ to $36 \pm 2.8 \mathrm{mg} \mathrm{g}^{-1}$ after $7 \mathrm{~d}$ of SSF can be attributed to the hydrolysis of cellulose and hemicellulose moieties into fermentable sugars, such as glucose. The fungus, $R$. oryzae is known to produce different intracellular and extracellular cellulolytic, hemicellulolytic, pectinolytic and amylolytic enzymes that can help in accessing the alternative carbon 

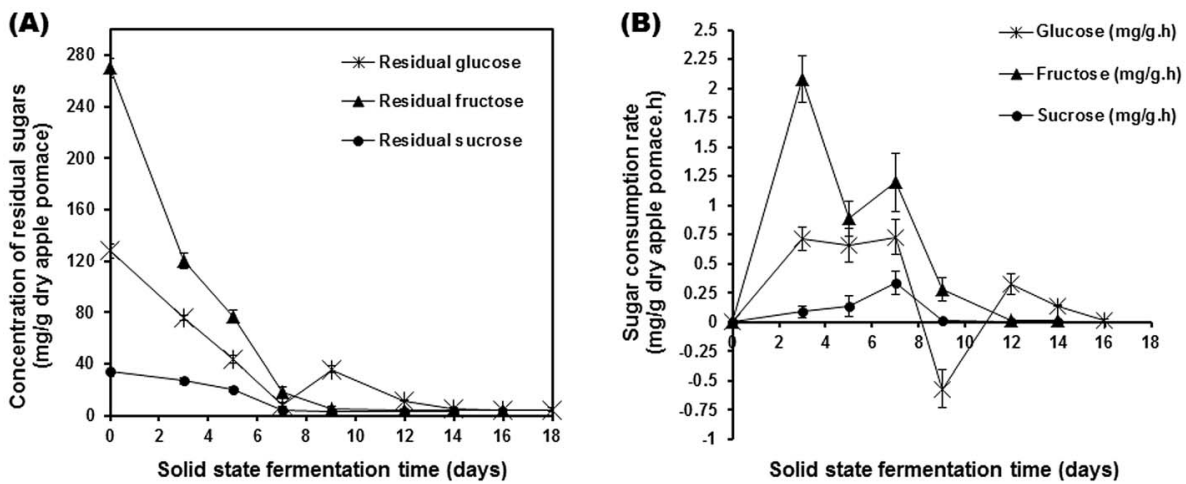

Fig. 3 (A) Changes in the concentrations (mg per g dry apple pomace) of residual glucose, fructose and sucrose and (B) changes in the consumption rate ( $\mathrm{mg}$ per $\mathrm{g}$ dry apple pomace per $\mathrm{h}$ ) of glucose, fructose and sucrose, during solid state fermentation under continuous rotation and with $50 \%(\mathrm{w} / \mathrm{w})$ of moisture content of apple pomace.

sources for metabolic activity and growth. ${ }^{41}$ Fibre compositional analysis of AP samples before and after SSF confirmed the utilization AP dietary fibres for FA production by the fungus. Discussion on this analysis has been detailed in the proceeding sub-section. In the present study, once the easily available hexose sugars were exhausted, the fungus started to feed on the structural fibres of AP. After $14 \mathrm{~d}$ of SSF, the residual glucose concentration was brought down suggesting utilization of both free and lignocellulose derived glucose for bioconversion into FA. Estimation of sugar moieties in the fermented AP samples confirmed the utilization and bioconversion of available carbon sources in AP into FA during SSF.

\subsection{Analysis of fibre composition of AP}

The fibre compositional analysis of AP showed changes in the content of TDF, IDF and SDF before and after SSF. The pre- and post-SSF estimated values of TDF, IDF and SDF are presented in Table 1. Before SSF, the TDF, IDF and SDF contents were around $39.4 \pm 1.5,32.5 \pm 0.7$ and $6.80 \pm 0.65(\% \mathrm{w} / \mathrm{w})$, respectively. After $21 \mathrm{~d}$ of SSF (under continuous rotation with $50 \% \mathrm{MC}$ ) the TDF, IDF and SDF contents were estimated to be $19.15 \pm 1.2$, $17.35 \pm 1.3$ and $2.3 \pm 0.45(\% \mathrm{w} / \mathrm{w})$, respectively.

The decrease in TDF was an interesting finding of the present study. It further confirmed the hydrolysis of cellulose and hemicellulose of AP by the activities of the enzymes released by the fungus $R$. oryzae during SSF. The monosaccharides derived were utilized as carbon source and bioconverted into FA. The decrease in IDF after SSF suggested solubilization of IDF constituents (cellulose and hemicellulose) by the fungal enzymatic action. This initially increased the SDF content but as the fungus started utilizing these sugar reserves,
SDF was almost exhausted after $18 \mathrm{~d}$ of SSF. As mentioned earlier, the glucose concentration was enhanced from $8.6 \pm 1.5$ to $36 \pm 2.8 \mathrm{mg} \mathrm{g}^{-1}$ after $7 \mathrm{~d}$ of SSF which further supported the increase in SDF during SSF.

\subsection{Viability check of $R$. oryzae during SSF}

The viability check of $R$. oryzae was carried out at different time intervals of SSF (under continuous rotation with $50 \% \mathrm{MC}$ ) and the obtained results are presented in Fig. 4. The inoculum contained a spore count of $1 \times 10^{7}$ spores per $\mathrm{g}$ dried $\mathrm{AP}$ samples. In the first $3 \mathrm{~d}$ of SSF, the spore count decreased to $5 \times$ $10^{4}$ spores per $\mathrm{g}$ dried AP samples. After $3 \mathrm{~d}$ of SSF, the spore count considerably increased and reached $3.2 \times 10^{8}$ spores per $\mathrm{g}$ dried AP samples at end of $7 \mathrm{~d}$ of SSF. From $7 \mathrm{~d}$ to $12 \mathrm{~d}$ of incubation, the spore count remained almost unchanged. Towards the last phase ( $12 \mathrm{~d}$ to $16 \mathrm{~d})$ of SSF, spore count decreased to $2.74 \times 10^{8}$ spores per $\mathrm{g}$ dried AP samples.

The initial decrease in the spore count from $1 \times 10^{7}$ to $5 \times 10^{4}$ spores per $\mathrm{g}$ dried AP samples during $0 \mathrm{~d}$ to $3 \mathrm{~d}$ of SSF was caused by the germination, mycelial propagation and adaption to applied fermentation conditions (colonization) of the fungus. ${ }^{19}$ However, the increase in the spore count during SSF suggested AP to be a good source of carbon and micronutrients for the fungus that supported sporulation, germination and then mycelial propagation. FA production profile recorded $3 \mathrm{~d}$ onwards also supported the higher metabolic activities of the fungus (Fig. 2).

\subsection{Phenolic content and profiling}

As presented in Table 1, the TPC of AP was considerably increased (by around $86 \%$ ) from $185 \pm 10.5$ to $345 \pm 8.5 \mathrm{mg}$ per $\mathrm{g}$ lyophilizate after $18 \mathrm{~d}$ of SSF under continuous rotation with $50 \% \mathrm{MC}$.

Table 1 Fibre composition (dry weight basis) and total phenolic content of apple pomace samples before and after solid state fermentation (values represent means \pm standard deviation of three analyses)

\begin{tabular}{lcccc}
\hline Apple pomace sample & $\begin{array}{l}\text { Total dietary } \\
\text { fibre\% }(\mathrm{w} / \mathrm{w})\end{array}$ & $\begin{array}{l}\text { Insoluble dietary } \\
\text { fiber\% }(\mathrm{w} / \mathrm{w})\end{array}$ & $\begin{array}{l}\text { Soluble dietary } \\
\text { fiber\% (w/w) }\end{array}$ & $\begin{array}{l}\text { Total phenolic content } \\
\text { (mg per g lyophilizate) }\end{array}$ \\
\hline $\begin{array}{l}\text { Before fermentation } \\
\text { After fermentation }\end{array}$ & $39.4 \pm 1.5$ & $32.5 \pm 0.7$ & $6.80 \pm 0.65$ & $185 \pm 10.5$ \\
& $19.15 \pm 1.2$ & $17.35 \pm 1.3$ & $2.3 \pm 0.45$ & $345 \pm 8.5$
\end{tabular}




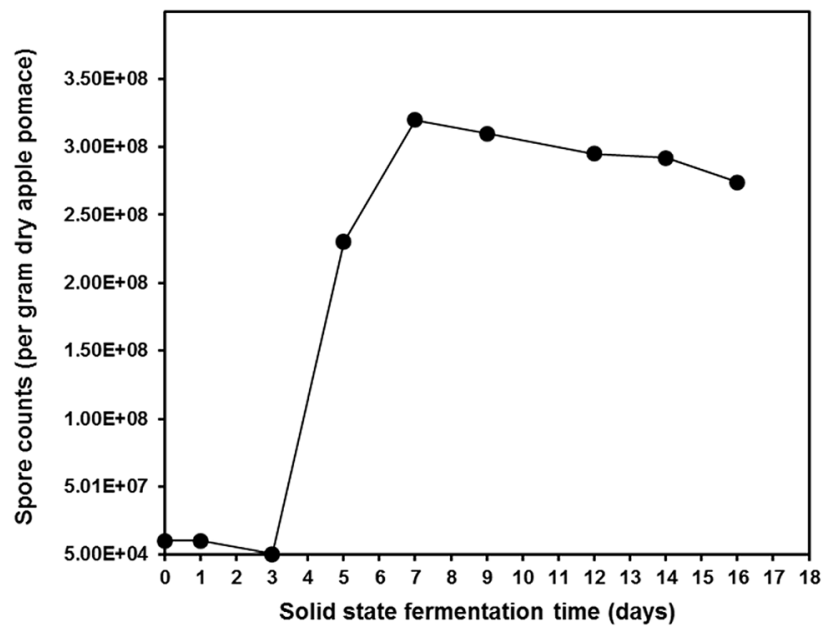

Fig. 4 Changes in the spore count (per gram dry apple pomace) of the fungus $R$. oryzae during solid state fermentation under continuous rotation and with $50 \%(\mathrm{w} / \mathrm{w})$ of moisture content of apple pomace.

LC/MS/MS profiling of AP samples showed the presence of some of the important phenolic acids viz. gallic acid, ferulic acid, 4amino-benzoic acid and vanillic acid and the phenolic aldehyde compound vanillin, as presented in Table 2 . Among the different phenolic acids, gallic acid, ferulic acid and vanillic acid displayed considerable increase in their content after $18 \mathrm{~d}$ of SSF. The increase in the contents for gallic acid, ferulic acid and vanillic were by around 6.2 folds (from $6.2 \pm 1.3$ to $38.56 \pm 3.6 \mathrm{mg}$ per $\mathrm{g}$ lyophilizate), 6 folds (from $13.54 \pm 2.7$ to $82.5 \pm 5.6 \mathrm{mg}$ per $\mathrm{g}$ lyophilizate) and 5.8 folds (from $7.23 \pm 1.4$ to $42.5 \pm 3.8 \mathrm{mg}$ per $\mathrm{g}$ lyophilizate), respectively. 4-Amino-benzoic acid content was almost doubled (from $3.4 \pm 1.1$ to $6.5 \pm 1.4 \mathrm{mg}$ per $\mathrm{g}$ lyophilizate), while vanillin content changed only marginally (from $1.8 \pm 0.35$ to $2.3 \pm 0.45 \mathrm{mg}$ per $\mathrm{g}$ lyophilizate).

Quantitative estimation of TPC before and after SSF confirmed the efficacy of the fungus $R$. oryzae in degrading AP under the applied SSF conditions. About $86 \%$ increase in total phenolic content after $18 \mathrm{~d}$ of SSF strongly suggested the release of different phenolics (free, esterified and insoluble-bound) from the hydrolyzable lignin and cellulose of AP. ${ }^{33}$ During SSF, the fungus utilized lignocellulosic moieties for nutrition and this caused the cleavage of the bonds of phenolics with lignin and

Table 2 Phenolic composition of apple pomace before and after solid state fermentation (values represent means \pm standard deviation of three analyses)

\begin{tabular}{lcc}
\hline & $\begin{array}{l}\text { Concentration } \\
\text { (mg per g lyophilizate) } \\
\text { before solid state } \\
\text { fermentation }\end{array}$ & $\begin{array}{l}\text { Concentration } \\
\text { (mg per g lyophilizate) } \\
\text { after solid state } \\
\text { fermentation }\end{array}$ \\
\hline Gallic acid & $6.2 \pm 1.3$ & $38.56 \pm 3.6$ \\
Vanillin & $1.8 \pm 0.35$ & $2.3 \pm 0.45$ \\
Ferulic acid & $13.54 \pm 2.7$ & $82.5 \pm 5.6$ \\
4-Amino-benzoic & $3.4 \pm 1.1$ & $6.5 \pm 1.4$ \\
acid & $7.23 \pm 1.4$ & $42.5 \pm 3.8$ \\
Vanillic acid & &
\end{tabular}

cellulose. For this purpose, filamentous fungi including $R$. oryzae use extracellular carbohydrolisases and ligninolytic oxidative system for the degradation of phenyl ring and it causes higher TPC. In order to grow and sporulate, $R$. oryzae degraded lignin of AP during SSF and released ferulic acid (a constituent of lignin). ${ }^{\mathbf{4 2 , 4 3}}$ As the SSF was carried out under aerobic conditions, there was a higher chance that most of the vanillin present in AP was oxidized into vanillic acid during SSF. As the initial vanillic acid content was lower, the enhancement in its content was the result of bioconversion of high vanillin (increased from $7 \mathrm{~d}$ to 12 d of SSF, data not shown) into vanillic acid. The estimation of TPC and profiling of phenolic compounds thus confirmed the biodegradation of lignocellulosic moieties of AP by the fungus, $R$. oryzae for its nutritional purpose.

\section{Conclusions}

From the present optimization study on the fumaric acid production using the rotating drum type solid-state bench scale bioreactor, it was confirmed that apple pomace worked as the sole source of carbon, micro and macro nutrients for the growth and reproduction of the fungal strain, Rhizopus oryzae 1526. The fungus bio-converted the sugars and lignocellulosic biomasses present in apple pomace into fumaric acid under optimum fermentation conditions. The maximum fumaric acid concentration (138 $\pm 9.1 \mathrm{~g} \mathrm{~kg}^{-1}$ at the end of 14 days) was obtained under continuous mode of rotation of the fermentor and with $50 \%$ moisture content $(\mathrm{w} / \mathrm{w})$ of apple pomace. Sugar consumption analysis confirmed the utilization of glucose, fructose and sucrose by the fungus for fumaric acid production. Analysis of apple pomace fibre composition also confirmed the conversion of insoluble dietary fiber into soluble dietary fiber and utilization of the dietary fibre for fumaric acid production. Viability check during fermentation showed maintenance of a high cell count of $2.74 \times 10^{8}$ spores per $\mathrm{g}$ dry apple pomace samples at end of 16 days. Total phenolic content analysis strongly suggested for biodegradation of lignin and cellulose moieties by the fungus during fermentation. LC/MS/MS profiling of AP samples showed the presence of different phenolic constituents (gallic acid, ferulic acid, vanillic acid, vanilli and 4-amino-benzoic acid) and changes in their content after fermentation. Enhancement in ferulic acid content confirmed lignin degradation, while higher content of vanillic acid suggested the maintenance of an aerobic condition during the solid-state fermentation. The outcome of the present investigation ensures the scale-up application of apple pomace for fumaric acid bioproduction.

\section{Acknowledgements}

Financial support from the Natural Sciences and Engineering Research Council of Canada (NSERC, Discovery Grant 355254), MAPAQ (No. 809051) and Ministère des Relations Internationales du Québec (Quebec-Vietnam 2012-2015) are sincerely acknowledged. FQRNT merit scholarship program for foreign student (MELS) is also acknowledged for financial assistance to Mr Ratul Kumar Das. 


\section{References}

1 R. A. Sheldon, Green Chem., 2014, 16, 950-963.

2 Q. Xu, S. Li, H. Huang and J. Wen, Biotechnol. Adv., 2012, 30, 1685-1696.

3 S. T. Yang, K. Zhang, B. Zhang and H. Huang, in Biobased Chemicals - Fumaric Acid, Comprehensive biotechnology, ed. M. Moo-Young, Elsevier, The Netherlands, 2nd edn, 2011, pp. 163-167.

4 C. A. Roa Engel, A. J. Straathof, T. W. Zijlmans, W. M. van Gulik and L. A. M. van der Wielen, Appl. Microbiol. Biotechnol., 2008, 78, 379-389.

5 U. Mrowietz and K. Asadullah, Trends Mol. Med., 2005, 11, 43-48.

6 D. Moharregh-Khiabani, R. A. Linker, R. Gold and M. Stangel, Curr. Neuropharmacol., 2009, 7, 60-64.

7 N. Shokri, H. A. Java, S. Fouladdel, A. Khalaj, R. Dinarvand and E. Azizi, Afr. J. Pharm. Pharmacol., 2011, 5, 797-805.

8 I. Goldberg, J. S. Rokem and O. Pines, J. Chem. Technol. Biotechnol., 2006, 81, 601-611.

9 R. K. Das, S. K. Brar and M. Verma, Pharmacol. Rep., 2015, DOI: 10.1016/j.pharep.2015.10.007.

10 www.grandviewresearch.com, accessed on 20 October 2015.

11 S. W. Kang, H. Lee, D. Kim, D. Lee, S. Kim, G. T. Chun, J. Lee, S. W. Kim and C. Park, Biotechnol. Bioprocess Eng., 2010, 15, 761-769.

12 T. Werpy, and G. Petersen, US Department of Energy, 2004, USA.

13 R. K. Das, S. K. Brar and M. Verma, J. Cleaner Prod., 2015, DOI: 10.1016/j.jclepro.2015.08.108.

14 C. Krishna, Crit. Rev. Biotechnol., 2005, 25, 1-30.

15 J. Sargantanis, M. N. Karim, V. G. Murphy, D. Ryoo and R. P. Tengerdy, Biotechnol. Bioeng., 1993, 42, 149-158.

16 K. S. M. S. Raghavarao, T. V. Ranganathan and N. G. Karanth, Biochem. Eng. J., 2003, 13, 127-135.

17 K. J. Carson, J. L. Collins and M. P. Penfield, J. Food Sci., 1994, 59, 1213-1215.

18 B. Suarez, A. L. Alvarez, Y. D. Garcia, G. Barrio, A. P. Lobo and F. Parra, Food Chem., 2010, 120, 339-342.

19 G. S. Dhillon, S. K. Brar, M. Verma and R. D. Tyagi, Biochem. Eng. J., 2011, 54, 83-92.

20 B. Gullon, E. Falque, J. L. Alonso and J. C. Parajo, Food Technol. Biotechnol., 2007, 45, 426-433.

21 R. Shalini and D. K. Gupta, J. Food Sci. Technol., 2010, 47, 365-371.
22 F. Vendruscolo, P. M. Albuquerque, F. Streit, E. Esposito and J. L. Ninow, Crit. Rev. Biotechnol., 2008, 28, 1-12.

23 F. Gassara, S. K. Brar, F. Pelletier, M. Verma, S. Godbout and R. D. Tyagi, J. Hazard. Mater., 2011, 192, 1178-1185.

24 www.hortcouncil.ca, accessed on 20 October 2015.

25 H. R. Lubowitz and E. G. La Roe, US Pat., 2861922, 1958.

26 I. Goldberg and B. Stieglitz, US Pat., 4564594, 1986.

27 L. B. Ling and T. K. Ng, US Pat., 4877731, 1989.

28 Y. Oda, Y. Yajima, M. Kinoshita and M. Ohnishi, Food Microbiol., 2003, 20, 371-375.

29 L. P. Dang, W. W. Du, S. Black and H. Y. Wei, J. Chem. Eng. Data, 2009, 54, 3112-3113.

$30 \mathrm{~W}$. Horwitz, Official Methods of Analysis of AOAC International, AOAC International, Maryland, 2000.

$31 \mathrm{H}$. Chen, G. L. Rubenthaler, H. K. Leung and J. D. Baranowski, Cereal Chem., 1988, 65, 244-247.

$32 \mathrm{~J}$. Reeb and M. Milota, Moisture content by the oven-dry method for industrial testing, Western Dry Kiln Association, Western Dry Kiln Association Meeting, Portland, 1999.

33 C. G. Schmidt, L. M. Goncalves, L. Prietto, H. S. Hackbart and E. B. Furlong, Food Chem., 2014, 146, 371-377.

34 Y. Zhou, J. Du and G. T. Tsao, Appl. Biochem. Biotechnol., 2000, 84-86, 779-789.

35 C. Gu, Y. Zhou, L. Liu, T. Tan and L. Deng, Bioresour. Technol., 2013, 131, 303-307.

36 M. L. Sudha, V. Baskaran and K. Leelavathi, Food Chem., 2007, 104, 686-692.

37 H. Chen, Principles of Solid-State Fermentation Engineering and Its Scale-Up, Modern Solid State Fermentation: Theory and Practice, ed. H. Chen, Springer, The Netherland, 1st edn, 2013, pp. 75-139.

38 P. Geravais, Water Relations in Solid-state Fermentation, Current Developments in Solid-state Fermentation, ed. A. Pandey, M. Fernandes and L. Christian, Springer, The Netherland, 1st edn, 2008, pp. 74-116.

39 J. J. Derksen and D. Eskin, FDMP, 2011, 7, 341-355.

40 Q. Xu, S. Li, Y. Fu, C. Tai and H. Huang, Bioresour. Technol., 2010, 101, 6262-6264.

41 B. Ghosh and R. R. Ray, Int. J. Appl. Sci., 2011, 11, 2470-2486. 42 C. Sánchez-Moreno, J. A. Larrauri and F. Saura-Calixto, J. Sci. Food Agric., 1998, 76, 270-276.

43 S. Martins, S. I. Mussatto, G. Martínez-Avila, J. MontañezSaenz, C. N. Aguilar and J. A. Teixeira, Biotechnol. Adv., 2011, 29, 365-373. 